\title{
Experimenting LiquidFeedback for Online Deliberation in Civic Contexts
}

\author{
Fiorella De Cindio and Stefano Stortone \\ Department of Computer Science, University of Milano \\ Via Comelico 39/41, 20135 Milano \\ \{fiorella.decindio, stefano.stortone\}@unimi.it
}

\begin{abstract}
The growing distrust in political institutions is accompanied by new opportunities for civic involvement through online technological platforms. LiquidFeedback is one of the most interesting, as it embeds innovative features to support online deliberative processes. This software has been designed as an intranet tool for closed and homogeneous groups but it has also recently been used in large civic context, involving generic citizens. Aim of the paper is discussing the potential of LiquidFeedback for these purposes, by presenting the preliminary analysis of the "ProposteAmbrosoli2013" initiative carried on, in occasion of the recent elections in the Lombardy region (Italy).
\end{abstract}

Keywords: LiquidFeedback, online deliberation, democracy, civic participation.

\section{Introduction}

The "endless" crisis of the western models of economy and democracy imposes a renewed effort to imagine and develop new forms of civic engagement (see for instance [13]). The persistent demands coming from the civil society organizations as well as from international organizations $[4,2]$ find more and more the concrete support of the ICTs. New software tools have been developed to facilitate knowledge sharing and the organization of new practices of crowdsourcing and collaboration. These tools are already being used by public bodies for opening government (see, e.g., [11]) and by the emerging grassroots organizations [3], to build up consultative and deliberative processes.

One of the most popular software tools for idea gathering is Ideascale (ideascale.com), already adopted in 2008 to support President Obama's Open Government Initiative, and afterward widely used worldwide. However, Ideascale has weak deliberative mechanisms to foster collaboration among participants: each proposal can be commented, voted, but not co-built. This enforces a competitive game among the proposals, as we observed in the case described in [10]. In this direction, a richer application is TOM (Estonian acronym of "Today I Decide"), developed within a state-initiated e-participation project launched in Estonia in 2001 and then proposed at the EU level (under the label TID+, http://tidplus.net) ${ }^{1}$. TOM is focused on

\footnotetext{
${ }^{1}$ Since 2007 TOM has been embedded into the broader participatory website www . osale . ee
} 
legislative proposals made by citizens through a deliberative process based on discussion and vote. After a fairly active beginning, participation gradually decreased, mainly due to the scarce commitment by the Government and little cooperative features for participants [8].

LiquidFeedback (LQFB in the following) is an open-source software that is recently generating much interest (e.g., [14]) precisely because of its innovative features, which are similar but more articulated than TOM/TID+: it also embeds a deliberative process through which proposals are not only debated and voted, but also supported, and written in a collaborative way, or questioned. In case of alternative options, proposals are voted using the Schultze method (see afterwards), a revised version of the Condorcet's one [15]. LQFB provides another innovative feature, the transitive proxy voting: participants can delegate (and then revoke) other members to make proposals and vote on their behalf in specific thematic areas and/or issues in which they are particularly keen on and trustworthy. These proxies can in turn choose other participants to transfer their votes again.

LQFB was conceived and designed to support the internal decision-making process of the German Pirate Party [7]. However, it also stands for representing a "political" platform whose aims is to reform democracy using technological means. Specifically, it does it by fostering an original mix of - rather than a competition between - direct and representative democracy. A liquid democracy, indeed.

Besides political parties and movements, LQFB is today promoted by a nonprofit association - Interaktive Demokratie ${ }^{2}$ - and has broadened its application fields. It is now adopted also by civil society organizations (e.g., Slow Food Germany) and local communities: e.g., since November 2012, the County of Friesland ${ }^{3}$ is testing LQFB for supporting civic participation and public deliberation. LQFB is a recent product and there is still no international literature that provides scientific insight about it.

Interest on LQFB has recently grown remarkably in Italy as well, where Internet is playing an extraordinary role in sustaining and supporting civic engagement against corruption and political decline [6]. The first Italian localization of LQFB is due to the Italian Pirate Party, but its widespread popularity on national media is related with its use by several local groups of the MoVimento 5 Stelle (5 Stars Movement, M5S in the following), a political movement created in 2009 by the comic actor Beppe Grillo after and through an intense use of the web (mainly his blog, daily visited by hundreds of thousands users) and social network sites, to oppose the moral decline of the Italian political class. Direct democracy, intense civic participation and the use of ICTs for public purposes, are the key issues for the M5S. It increases its popularity and rapidly reaches a major role in the political arena: it is now the second political party in Italy.

Pushed by the renewed political scenario, LQFB has recently been used within initiatives open to generic citizens. The first trial, called Libera Sicilia, took place in occasion of the Sicilian regional elections (September 2012) by a small party of the left coalition: the goal was to collect citizen ideas for its political program. Shortly later, the popular TV show Servizio Pubblico (Public Service) launched a much

\footnotetext{
2 http: / /www.interaktive-demokratie.org/

${ }^{3}$ https://www.liquid-friesland.de/lf/index/index.html/
} 
broader initiative, called "Liquid Party": however, the goal of gathering ideas from the audience of the show was not at all clear. No one of these two trials was significant enough to test the possibility for LQFB to enable purposeful and extensive initiatives of civic participation.

An experiment with such characteristics and goals has been undertaken by the RCM Foundation ${ }^{4}$ and by the University of Milan in occasion of the anticipated regional elections in the Lombardy region, scheduled in February 2013. This paper describes and analyses this initiative, that we call hereinafter ProposteAmbrosoli2013. In particular, it presents the project timeline and the design choices (section 2) and a preliminary analysis of its outcomes (section 3). The conclusions develop some insights over the question if LQFB can foster online deliberation in civic contexts.

\section{LiquidFeedback for Civic Participation: Design Choices}

The Lombardy regional Council resigned on Oct. $26^{\text {th }}, 2012$, as a result of massive corruption scandals which affected many of the leading politicians, including the Governor who has been in charge for 17 years. In the context of a large political disaffection, the primary elections of the left-coalition chose Umberto Ambrosoli - a criminal lawyer with a civil profile rooted in his father's history ${ }^{5}$ - as candidate for running as Governor of the Region. He had to compete with the candidate of the right-coalition, Roberto Maroni, former Ministry of the Interiors in the Berlusconi's government. Largely supported by several member of the civil society, Umberto Ambrosoli is a relatively young (40 years old) independent candidate, not well-known outside the city of Milan, but still politically active.

The first talk for promoting a LQFB-based participatory initiative, so enforcing his electoral profile (and, implicitly, competing with the M5S growth too) occurred on Nov. $17^{\text {th }}$. The decision of doing it arrived on Dec. $18^{\text {th }}$, when Ambrosoli won the primary elections. Since the election day was scheduled for Febr. $24^{\text {th }}$, the time for designing the website, configuring the software, and launching the initiative (on Jan. $3^{\text {rd }}$ ) was then very short: just two weeks, including a couple of days for the beta testing. Nevertheless, this short period was characterized by an intense discussion over the design choices and a coordinated activity between the developers, the candidate and his staff. A direct contact with the system administrators of the Libera Sicilia website was particularly useful to learn from their experience.

Before presenting in $\$ 2.2$ the main design choices done for configuring the website www.proposte.ambrosolilombardia2013.it (website, hereinafter), let us introduce the LQFB basic concepts and its relevant terminology.

\subsection{LiquidFeedback Basic Concepts}

LQFB is a purely deliberative tool, with no free discussion and forum-like facilities. It has a rich and articulated structure, which is not easy to catch through its extremely

\footnotetext{
${ }^{4}$ RCM Foundation has been established since 1994 as a spin-off of the Civic Informatics Laboratory of the University of Milan.

5 see. e.g., http://en.wikipedia.org/wiki/Giorgio_Ambrosoli
} 
"essential", almost text-based, user interface. To make the tool (more) within everybody's reach, an online help, developed in [12], was implemented in the section "Liquid Help" of the website. The Fig. 1 is adapted from it and represents, respectively: (a) the structure of the "issue" (or proposal) which is the basic concept/object in LQFB (bottom left side of the figure); (b) the state chart representing the states through which an issue evolves from its creation to its approval or rejection (right side); (c) the organization of the issues in a "tree" structure consisting of thematic sections and areas (top left). We use the terminology of the LQFB 2.2 version of the official LQFB distribution, which provides the English, German and Italian interfaces.

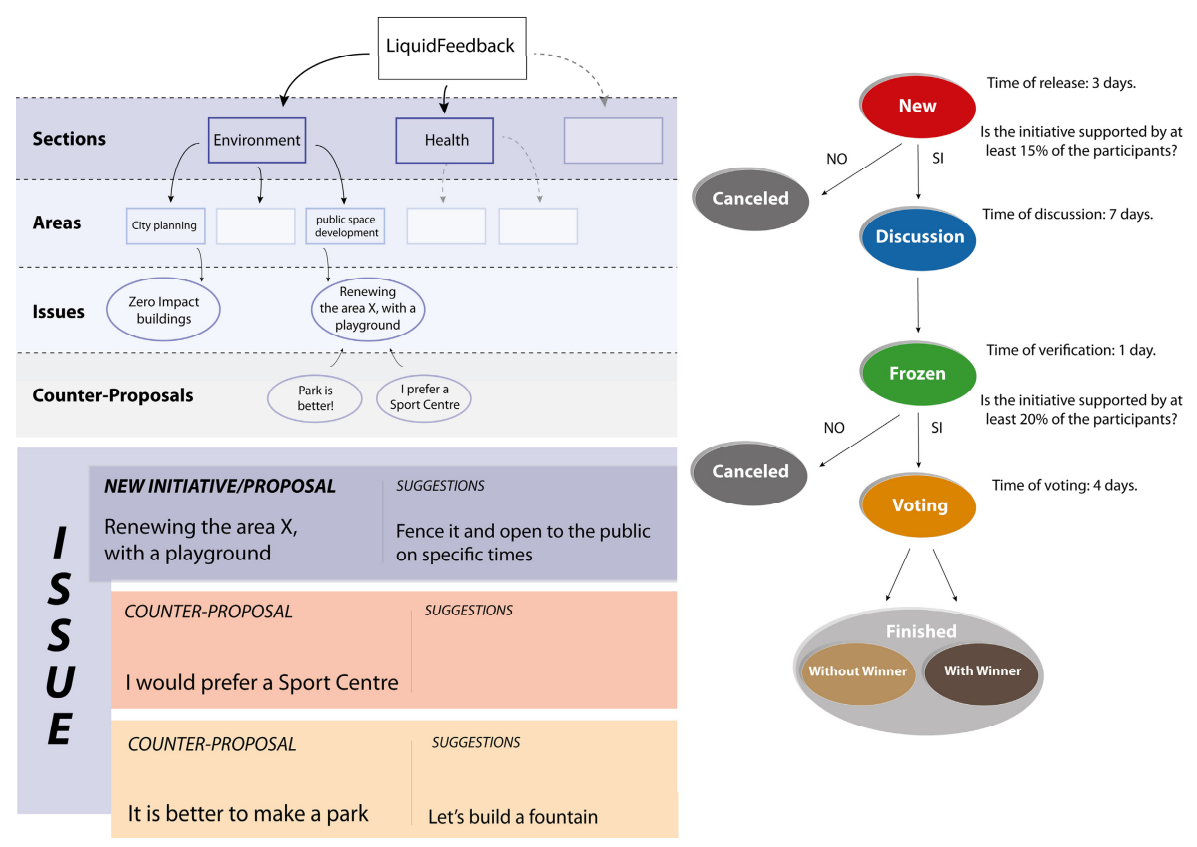

Fig. 1. Excerpt from the Liquid Help

1. The issue consists of a (preliminary) proposal to solve a problem. When created, the issue gets an identifier, e.g., i252, where "i" stands for "initiative". This means that LQFB does not distinguish between the issue and the original proposal. Any proposed initiative can be disputed by other users through the proposition of new initiatives that get different identifiers. Proposals and counter-proposals can be supported and can collect suggestion(s) which prompt the authors to reformulate their proposals. Examples in Fig. 1 (bottom left) can help to understand the relation among issues, initiatives and suggestions.

2. Each issue goes through a deliberative path, consisting of subsequent states: New, Discussion, Frozen, Voting. The state transition occurs according to conditions depending on time (e.g., after four days of discussion) and/or a "quorum" (e.g., if 
the proposal gets at least the $20 \%$ of supporters, out of the whole participants potentially interested in that issue). The time and quorum parameters are chosen at configuration time and can be changed, e.g., to match with an increased number of registered users. Proposals which get sufficient support are firstly frozen (to allow participants to read the final version) and then voted. All the proposals facing with the same issue are voted together: voters express positive, neutral or negative opinions on them, together with priorities. Results, i.e., "winning" (or approved) proposals, are calculated with the Schultze algorithm.

The above LQFD deliberative path somehow recalls, but looks richer of, the one included in the above mentioned Estonian e-participation project.

\subsection{Design Choices}

Consistently with the guidelines for the design of deliberative digital habitat presented in [5], the main design choices concern the "participatory contract" that binds the various social actors: in this case, the candidate, owner of the website, and the citizens who advance proposals. This "participatory contract" must be realistic and trustable to both sides, and then articulated by specifying: the participants' authentication policy; the setting of the parameters which define the conditions regulating the transition of proposals from one state to another; the embedding of LQFB into a richer website. We briefly discuss them here below.

a) The definition of the participatory contract: participants were asked to provide specific proposals to refine and detail the (already published) candidate's political program, whose organization in thematic areas was reflected into the LQFB structure (sections and areas). To make the "game" trustable and attractive to citizens, the candidate committed himself to provide feedback about the approved proposals, either accepting or rejecting them. The platform was open to any citizens, not only to Ambrosoli's supporters. On the other side, citizens were asked to look at the candidate's program and at the functioning of LQFB, before formulating proposals. The importance of the participatory contract was emphasized by publishing it with major evidence in the website home page (through a big button "Read the Participatory Contract"). The RCM Foundation played as trusted third party, warrantor of the agreements.

b) The participants' authentication policy: in LQFB, participants' registration occurs upon an invitation from the administrator of the platform. To get it, citizens had to fill a very detailed form including the fiscal code (which is in Italy each one's personal ID). This guarantees a strongly committed community of concerned citizens and allows LQFB to work without any moderation facility.

c) Configuration parameters setting: LQFB configuration includes the setting of a wide set of parameters which shape the deliberative path of the proposals, by regulating the transition from one state to another. These include: (1) the first quorum for the proposal to enter in the "discussion" state; (2) the second quorum for going to vote; (3) the largest duration of each phase and (4) the minimum number of positive votes for the proposal to be approved. These choices influence 
the amount of proposals which are finally approved. In the context of a (short and competitive) electoral campaign, the objective was to fulfill participants' expectation to see their proposals considered but, at the same time, to foster some collaboration and aggregation among participants, and to avoid too many proposals for the candidate to consider. Finally, the two quorums were respectively set to the $10 \%$ and $15 \%$; the maximum duration of the deliberative path of a proposal was set to 15 days; the minimum number of positive votes each proposal needs was three.

d) Embedding LQFB into a richer website: since LQFB has a very spartan interface, a more user-friendly website embeds it. It runs on the open-source software platform openDCN (openDCN.org), which also provides social media sharing facilities. This "case" website has TABs which link to its various sections. For the purpose of this paper it is worth mentioning: (a) the LiquidFeedback section, actually running on a different server; (b) the Liquid Help section; (c) the so called Diary of Participation, a kind of blog, where each single winning proposal was published by its proposer; it also hosts the feedback from Ambrosoli, either as comments to proposals or as autonomous posts.

\section{Analysis}

The following, still preliminary, analysis of the initiative is mainly based on the data coming from the registration and LQFB databases, collected in the period between Jan. $1^{\text {st }} 2013$, and Febr.22 ${ }^{\text {nd }}$, when the electoral period closed. We will also take into account data from the logfiles of the two websites (one running LQFB, the other running openDCN). Finally, we will highlight some of the results of a survey administered online on Febr. $22^{\text {nd }}$ and returned before the results of the elections.

Tab. 1 summarizes the participatory activity in ProposteAmbrosoli2013. During the above period (53 days), 1320 citizens filled the form to be invited to participate in LQFB. 1120 (the 85\%) completed the procedure and activated their profile: we will call them "participants". The remaining $15 \%$ could have been "victim" of the demanding registration procedure. The picture of the participant's population, as it comes out from enrollment data, shows a prevalence of middle-aged men, while young people between 18 and 24 are under-represented (4,3\%).

Table 1. Participatory activities in ProposteAmbrosoli2013

\begin{tabular}{|l|l|l|}
\hline Actions & Nr.. & Participants (1120 enrolled) \\
\hline propose & 239 & 134 \\
\hline suggest & 225 & 87 \\
\hline support & 1099 & 517 \\
\hline vote & 1002 & 298 \\
\hline at least one action & ---- & 609 \\
\hline
\end{tabular}


239 proposals were created by 134 participants (the 12\%): the 90\% (121) of them created 1, 2 or at most 3 proposals, which represent the $69 \%$ of the overall proposals. This first category of "standard" proposers is complemented by a group of 13 "superactive" proposers who did the remaining 75 proposals (31\%). The act of proposing ideas were then quite well distributed (see Fig. 2) over the active participants' population. Participation does not only consist in submitting, but also in debating, improving and supporting already submitted proposals: 87 participants contributed to improve the quality of the proposals with 225 suggestions; 45 of them were also proposers, while 42 were not. Proposals were finally supported by 517 participants, ranging from 1 to 61 supports each and 1099 in total; 345 supporters were neither proposers nor contributors. The activities performed in the initial steps of the whole deliberative process allowed 113 out of the 239 submitted proposals (the 47\%) to fulfil the policy settings and reach the voting phase. These 113 finalists came from 78 different participants, without significant distinction between "standard" or "superactive" proposers.

Voters were less than supporters: 298 participants expressed 1002 votes for the finalist proposals. One third of the proposers of finalist proposals did not even voted their own proposal. 90 of the voters were "virgin" of any other activity, 239 were not proposers. The voting phase was also characterized by the absence of disagreement: 876 votes were positive, only 22 negative and 104 were neutral. That is to say, few participants disagreed on the proposals or deemed important to vote against them: only two of the voted issues had counter-proposals, and 109 of the 113 finalists proposals (the $96,5 \%$ ) were approved while only four did not.

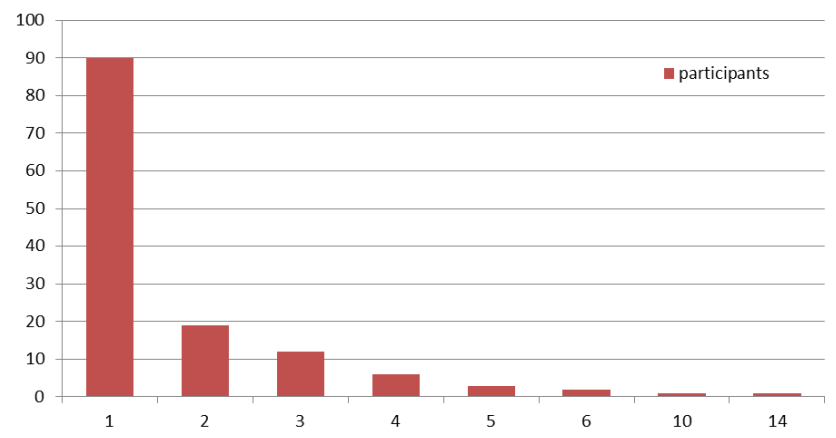

Fig. 2. Distribution of proposers according to the number of their proposals

Among the approved proposals, one stood out from the rest because of the high number of supporters and voters. It gathered 180 supporters and 113 voters, while the average of votes for the other proposals was 8,09, with an upper bound of 28 votes. This situation is a clear case of lobbying, as it was the coordinated action of an interest group to sustain a specific proposal. This (very well-articulated) proposal was posted by the leader of a health association and was about its mission. The proposer invited hundreds of friends and members of the association to participate to LQFB and support the proposal. We can imagine that he gave them directions to perform the 
appropriate actions at the appropriate time: firstly, by supporting, and then voting "their" proposals. Such a huge amount of supporters and voters was not really necessary to fulfill the policies and had the effect of unveiling the lobbying group.

Delegation, one of the LQFB key-action, deserves special attention since basically nobody used it. In the survey, we investigated the reasons of such behavior, with the following result: the $25 \%$ of the respondents just did not know about this action; the $20 \%$ did not understand its meaning, the $13 \%$ found it useful but did not whom to delegate, while the $26 \%$ simply preferred to vote personally. Only three of the respondents $(2 \%)$ used the delegation feature. The $14 \%$ did not answered at all. We believe that this result was because delegation is an innovative and unexpected feature within an initiative of civic participation, and it is also unusual in the web 2.0 where people are used to vote everything s/he "likes". More time and some explicit action to enforce it, could have overcome these hindrances and favor its use.

Up to now, we studied the behavior of the active users. Now we look to the 511 citizens (of the 1120, the 46\%) who enrolled in LQFB, but never performed any of the above actions. Comparing their account activation date and their last login, we have found that 404 of the 511 never logged in again after the registration. We can suppose that either they were blocked because of the low usability of the platform (as the open answers of the questionnaire suggest) or they enrolled mainly because of curiosity (due to the media attention on the platform). The motivations of this behavior need to be further investigated: was it really passive or was it coupled with reading activities which do not require to $\log$ in? What about the motivations of the other 286 citizens who also never logged in again after the first day but performed one single action?

Besides the raw values, the "participation trends" are also worth of attention. Fig 3 and Fig. 4 show that new enrollments and new proposals were concentrated in the first three weeks: during this period 700 members $(63 \%)$ enrolled in the platform and created 200 proposals, the $84 \%$ of the total. In both cases, the peaks occurred in two occasions: the first one, around Jan. $4^{\text {th }} 104$ new participants and 30 new proposals), after the issuing of the press release of the initiative and its launch on the candidate's Facebook page; the second one around Jan.14 ${ }^{\text {th }}$ (48 participants and 19 proposals), after the official opening of the campaign, when the candidate, in front of thousands of people and in live streaming, invited people to contribute. The further enrollment peak in Fig. 3 in early February is due to the above mentioned lobbying case on a single proposal and therefore does not appear in Fig. 4.

Apart the case of lobbyism, it seems that the initiative reached most of the interested citizens, who quickly started to contribute, at its very beginning, when the Ambrosoli electoral staff did the most intense promotional campaign on the candidate's social media channels. After that, they were more and more absorbed by the hard electoral campaign, thus reducing their commitment to the initiative. Moreover, as the proposals began to finish their deliberative path in LQFD, and those approved were published in the Diary of Participation, participants' attention moved from LQFB towards the "case" website. This trend is registered by the statistics of the two servers (Fig. 5) which reproduces the trend of Fig. 3 and Fig. 4, but shows that the "case" website server lost less Unique Visitors and Pages Visited than the LQFB server.

To conclude the analysis of the participatory process, we have to say that 92 of the 120 winning proposals were published by the proposers in the Diary of Participation. Ambrosoli commented three of them separately, while he discussed in four comments 
other 22 proposals, somehow related each other. In the whole, 25 of the 92 published proposal $(27 \%)$ got a feedback. Nevertheless, in his last post, close to the Election Day, he confirmed the commitment to consider all the approved proposals, after the elections, when he would govern the Region. Electoral results were different: on Febr.26 ${ }^{\text {th }}$ Roberto Maroni won the elections with the $42,81 \%$ of the votes, while Ambrosoli got the $38,24 \%$ of the votes.

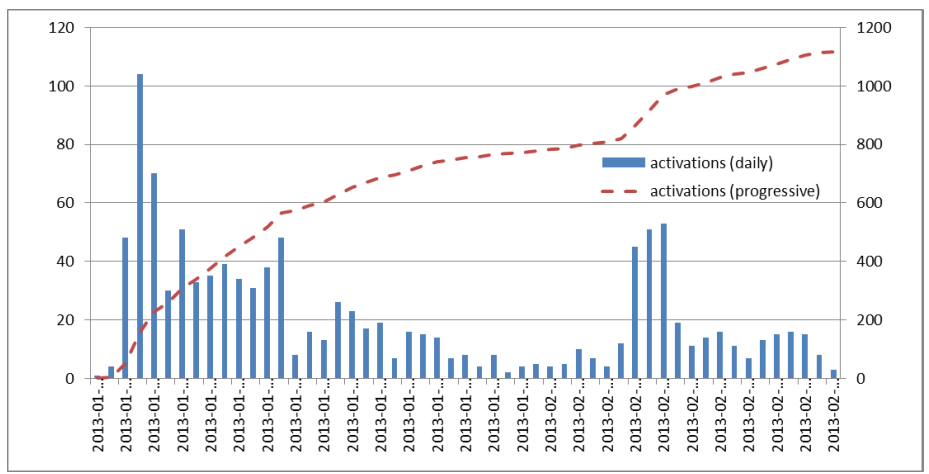

Fig. 3. Trend of enrollment of participants

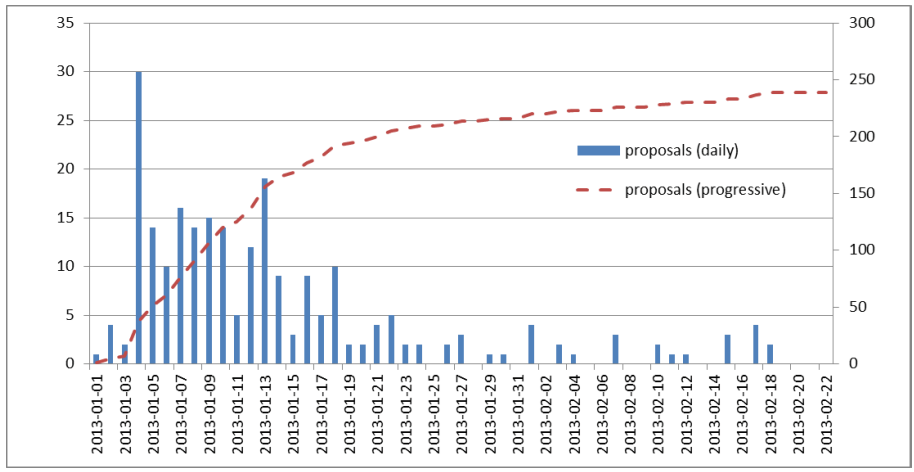

Fig. 4. Trend of creation of proposals

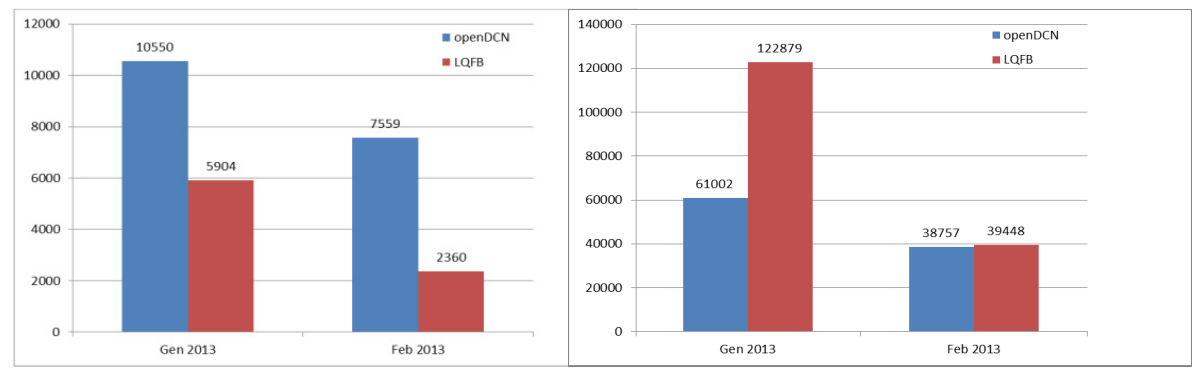

Fig. 5. Number of Unique Visitors and Pages Visited in openDCN and LQFB 
Despite all, the decreasing participation does not seem to mean a negative opinion about the initiative. In fact, if we look at the results of the survey, over a scale from 1 to 6 , more than three fourths of the respondents gave a positive evaluation (between 4 and 6) to the usefulness of four actions of LQFB: proposing, suggesting, supporting and voting; more than the half rated them between 5 and 6. The questions: "Is LQFB useful to generate valid, reasonable and shared proposals?" and "Can LQFB be used to build an effective participatory government?" got similar good results. Despite the large criticism with regards to the unfriendly user interface, explicitly expressed in the open answers, LQFB is widely considered as a valid deliberative tool.

\section{Conclusion}

In the paper on "Web Science", Hendler, Shadbolt, Hall, Berners-Lee, \& Weitzner [9] recognize the role of the web to "encourage more human engagement in the political sphere." They also point out the need of carrying on experiences in real-life settings so that "successful models evolve through trial, use, and refinement." One relevant phase in the proposed applications' life-cycle is therefore the analysis of the real-life trials, which has to figure out what worked quite well, what didn't. When possible, the analysis should compare similar experiences, but this may be difficult when facing with innovative applications. This is precisely the case we have studied in this paper: the use of LQFB for civic participation and public deliberation.

In this last section, we firstly sketch some conclusions from the analysis presented in section 3. We then integrate this "internal" assessment with some elements of comparison that can be drawn from the two cases: Libera Sicilia (whose administrators provided us with some data from their logfiles) and the County of Friesland, through direct online inspection and one indirect source.

The first overall remark is that the whole set of deliberative features of LQFB were used less than one could expect. We already discussed about the missed use of delegation. We also discussed the reasons why the setting of the configuration parameters left the quorum deliberately low. The third group of seldom used deliberative features concerns the voting phase. The short time of the pilot and the quite homogeneous population involved in it (due to the electoral nature of the initiative) may be the reasons for the few counter-proposals and negative votes. Therefore, the Schultze algorithm for rating alternative proposals was not tested, and the vote actually reduces to a "yes/no" choice. The voting phase thus loses its role (the $96,5 \%$ of the voted proposals were approved) and often voters were less than the supporters of the proposals.

Because of the combined effect of all these circumstances - ultimately related to the very short electoral period - we can say that LQFB was "de facto" used as an idea-gathering tool. Nevertheless, its deliberative and collaborative nature supported the fair selection of an half of the submitted proposals and enabled some cooperation around them: as Tab. 1 shows, participants were not only willing to submit their own ideas, but also open to support others' ones. This contrasts with the competitive game enforced by other idea gathering tools, observed, for instance, in Ideascale [10], 
where the activity of participants is often addresses not only to promote their own ideas, but also to vote against the competing ones.

Further insights can be drawn exploiting the little we know about the Libera Sicilia and the County of Friesland cases.

Libera Sicilia and ProposteAmbrosoli2013 were similar as they were both performed in a regional electoral context to involve citizens in the definition of the political program of one candidate Governor. In Libera Sicilia participants were much less than in ProposteAmbrosoli2013 (315 vs. 1120) and only 45 proposals (vs. 239) were created in a similar period of time ( 6 weeks vs. 7 weeks). The two initiatives share a similar percentage of proposals admitted to vote $(46 \%$ vs. $43 \%)$, mainly due to the similar quorums (20\%-20\% vs. 15\%-20\%), but in Libera Sicilia, proposals got fewer votes per voted proposal than in ProposteAmbrosoli2013 (4,09 vs. 8,09). These different outcomes would more probably depend on the higher electoral relevance of Ambrosoli and his political coalition, with respect to the Sicilian candidate. However, we believe that citizens were also attracted by the more trustable "participatory contract". In Libera Sicilia, the LQFB section was promoted by the misleading slogan that citizens would have developed the political program of the candidate. Unfortunately, the program was already written and published online. The "participatory contract" thus became unrealistic and not trustable. In ProposteAmbrosoli2013, instead, participants were asked to provide specific proposals in order to refine, specify and detail the candidate's political program, whose thematic sections were reflected into the LQFB structure. Moreover, through short but effective videos, the candidate substantiates his commitment into the initiative and his interest in considering citizens' suggestions.

The case of Liquid Friesland seems to confirm the importance of a strong "participatory contract". Here, the County Council adopted a resolution that commits it to discuss by law all the proposals approved through the LQFB deliberative process. In the first two and a half months, 500 out of 100.000 inhabitants joined LQFB (and we suppose they further increased in the meantime) and almost 50 proposals have been created to date. As in ProposteAmbrosoli2013, there has been a progressive decreasing activity in terms of proposals and votes. The bigger difference is in the higher number of citizens (up to 80) voting each single issue, as well as in the presence of several negative votes, something not observed in ProposteAmbrosoli2013. These are symptoms of the existence of contrasting positions and of a not homogeneous population. This also generates some counter-proposals, enabling the actual use of the Schultze algorithm in the voting phase. Liquid Friesland seems to encourage the use of LQFB by a local political institution willing to involve its citizens in a decision-making process with actual impact in the real life.

In conclusion, we believe that the preliminary analysis of the ProposteAmbrosoli2013 case study, carried on in this paper, motivates the increasing interest in LQFB. On the one hand, a more qualitative investigation is now going on in cooperation with the University of Trento and the Ahref Foundation (www.ahref.eu/en). On the other hand, while similar initiatives are blossoming in Italy, the Ambrosoli's platform is being re-activated for supporting his activity as member of the Regional Council of Lombardy. All this will provide additional empirical data to understand if and how LQFB can effectively foster online deliberation in civic contexts. 
Acknowledgement. We wish to thank Umberto Ambrosoli and his staff; the RCM Foundation staff, Davide Mezzera, and all the people mentioned in the Credit Section of the website. We are also grateful to the anonymous referees for their useful comments.

\section{References}

1. Ambrosoli, U.: Qualunque cosa succeda. Sironi editore, Milano (2009) (in Italian)

2. Caddy, J., Vergez, C.: Citizens as partners: Information, consultation and public participation in policy-making. OECD Publishing, Paris (2001)

3. Castells, M.: Networks of Outrage and Hope: Social Movements in the Internet Age. University of California, Berkeley (2012)

4. Council of Europe, Committee of Ministers, Rec, 19 of the Committee of Ministers to member states on the participation of citizens in local public life (2001), https: //wcd.coe. int/com. instranet. InstraServlet? command=com . instranet. $\mathrm{CmaBlobGet} \&$ Instranet Image $=871858 \&$ SecMode $=1 \& \mathrm{Doc} I d=2$ $34770 \&$ Usage $=2$

5. De Cindio, F.: Guidelines for Designing Deliberative Digital Habitats: Learning from eParticipation for Open Data Initiatives. The Journal of Community Informatics 8(2) (2012); Davies, T., Bawa, Z. (eds.) Special Issue: "Community Informatics and Open Government Data"

6. De Cindio, F., Schuler, D.: Beyond Community Networks: From Local to Global, from Participation to Deliberation. The Journal of Community Informatics 8(3) (2012); Horelli, L., Schuler, D. (eds.) Special Issue: "Linking the Local with the Global within Community Informatics"

7. Domanski, D.: Democratization through social innovation - pirate party Germany and new methods of civic participation. Paper Presented at The Second ISA Forum of Sociology, Buenos Aires, Argentina, August 1-4 (2012)

8. Glencross, A.: E-Participation in the Legislative Process: Procedural and Technological Lessons from Estonia. eJournal of eDemocracy \& Open Government 1(1), 21-29 (2009)

9. Hendler, J., Shadbolt, N., Hall, W., Berners-Lee, T., Weitzner, D.: Web science: An interdisciplinary approach to understanding the web. Communications of the ACM 51(7), 60-69 (2008)

10. Lanfrey, D., Solda-Kutzmann, D.: Progetto ConsultazionePubblica.Gov.It. In: "I Media Civici in ambito parlamentare", Senato della Repubblica (May 2013) (in Italian), http: / /www. senato.it/295

11. Lathrop, D., Ruma, L. (eds.): Open Government. Collaboration, Transparency, and Participation in Practice. O'Reilly, Sebastopol (2010)

12. Mezzera, D.: Realizzazione di un ambiente di deliberazione online basato su LiquidFeedback. BA thesis, Università di Milano (December 2011) (in Italian)

13. Revelli, M.: Finale di partito. Einaudi, Torino (2013) (in Italian)

14. Schuler, D.: Creating the World Citizen Parliament. ACM Interactions XX.3, (May+June 2013)

15. Schulze, M.: A new monotonic, clone-independent, reversal symmetric, and condorcetconsistent single-winner election method. Social Choice and Welfare 36(2), 267-303 (2011) 